\title{
Postoperative phosphodiesterase type 5 inhibitor administration increases the rate of urinary continence recovery after bilateral nerve-sparing radical prostatectomy
}

Giorgio Gandaglia, ${ }_{1}^{1}$ Maarten Albersen, ${ }^{2}$ Nazareno Suardi, ${ }_{1}^{1}$ Andrea Gallina, ${ }^{1}$ Firas Abdollah, ${ }^{1}$ Fabio Castiglione, ${ }^{1}$ Umberto Capitanio, ${ }^{1}$ Andrea Salonia, ${ }^{1}$ Patrizio Rigatti, ${ }^{1}$ Petter Hedlund, ${ }^{1}$ Francesco Montorsi ${ }^{1}$ and Alberto Briganti ${ }^{1}$

${ }^{1}$ Department of Urology, Urological Research Institute, University Vita-Salute San Raffaele, San Raffaele Scientific Institute, Milan, Italy; and ${ }^{2}$ Department of Urology, University Hospitals Leuven, Leuven, Belgium

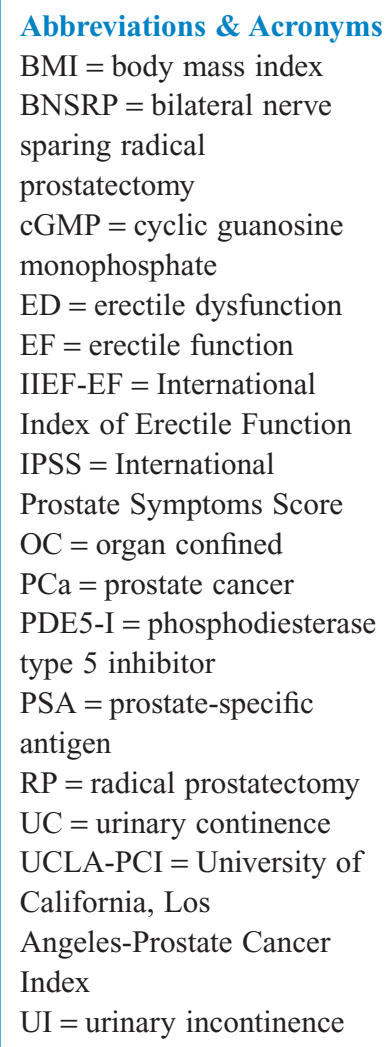

Correspondence: Alberto Briganti M.D., Department of Urology, Urological Research Institute, University Vita-Salute San Raffaele, Via Olgettina 58, Milan 20132, Italy. Email: briganti.alberto@hsr.it

Received 6 June 2012; accepted 10 August 2012.

Online publication 12

September 2012
Objectives: To investigate the effect of phosphodiesterase type 5 inhibitor on urinary continence recovery after bilateral nerve-sparing radical prostatectomy.

Methods: We analyzed data of 393 open bilateral nerve-sparing radical prostatectomies carried out between 2005 and 2010. Patients who recovered urinary continence within the first month after catheter removal $(n=52)$ were excluded. This resulted in 341 evaluable patients. Urinary continence recovery was defined as being completely pad free over a period of $24 \mathrm{~h}$. Patients were stratified according to postoperative daily $(n=58 ; 17 \%)$, on-demand $(n=112 ; 32.8 \%)$ and no $(n=171 ; 50.1 \%)$ phosphodiesterase type 5 inhibitor use. The effect of phosphodiesterase type 5 inhibitor use on urinary continence was assessed using the Kaplan-Meier method. Uni- and multivariable Cox regression analyses were used to test the association between phosphodiesterase type 5 inhibitor and urinary continence recovery after adjusting for cofounders.

Results: At a mean follow up of 36.4 months after surgery (median: 33), 288 patients (84.5\%) recovered urinary continence after bilateral nerve-sparing radical prostatectomy. Patients who did not use phosphodiesterase type 5 inhibitor after surgery had lower rates of urinary continence recovery at 1- and 2-year follow up as compared with patients taking phosphodiesterase type 5 inhibitor (67.1 vs $86.7 \%$ and 76 vs $94.4 \%$, respectively; $P<0.001)$. After adjusting for all confounders, multivariable analysis showed that phosphodiesterase type 5 inhibitor use, either on demand or daily, had a positive impact on urinary continence recovery $(P=0.03)$.

Conclusions: Patients taking phosphodiesterase type 5 inhibitor have higher urinary continence recovery rates as compared with patients left untreated after bilateral nervesparing radical prostatectomy. An improvement in sphincteric and pelvic floor blood supply might be responsible for this beneficial effect associated with the use of phosphodiesterase type 5 inhibitor.

Key words: nerve sparing, phosphodiesterase type 5 inhibitors, prostate cancer, radical prostatectomy, urinary continence recovery.

\section{Introduction}

$\mathrm{RP}$ is a commonly used treatment option for patients with clinically localized PCa and a life expectancy of at least 10 years. ${ }^{1}$ The most common sequelae of this procedure are UI and ED, which significantly affect health-related quality of life after surgery. ${ }^{2}$ Such quality of life issues are of increasing importance, as the introduction of PSA-based screening programs has contributed to a shift towards younger age and earlier PCa stage at diagnosis. ${ }^{3}$ For these reasons, when technically feasible and oncologically indicated, a bilateral nervesparing approach is carried out. ${ }^{4}$ This approach is aimed at providing an optimal oncological outcome while aiming for maximal preservation of the anatomical structures devoted to 
both urinary and sexual function. However, a proportion of patients still experience UI and ED after surgery, with a significant negative impact on quality of life. $^{2}$ It is well known that administration of PDE5-I, either in a daily or on demand fashion, can lead to an improvement in the recovery of EF postoperatively. ${ }^{5,6}$ Previous studies have also shown that PDE5, as well as cGMP and the cGMP-dependent protein kinase-1, are expressed in the human lower urinary tract, including the prostate, bladder and urethra. ${ }^{7-10}$ In particular, PDE5 is expressed within smooth muscle fibers of supplying arteries of pelvic organs. ${ }^{8-10}$ Although these findings have led to a surge of reports addressing the effect of PDE5-I on lower urinary tract symptoms in patients suffering from benign prostatic hyperplasia, ${ }^{11}$ few data are available on the possible effects of PDE5-I on UC recovery after BNSRP. ${ }^{12}$ Administration of PDE5-I might indeed improve pelvic blood flow and oxygen supply, with a beneficial effect on sphincter function. It is, however, not known if this might impact on UC recovery after BNSRP.

The aim of the present study was to investigate the effect of different PDE5-I administration schedules on UC recovery in a large population of patients treated with retropubic BNSRP at a single high-volume center.

\section{Methods}

The present study included 393 patients with $\mathrm{PCa}$ who underwent retropubic BNSRP with or without pelvic lymph node dissection at a single tertiary referral center between January 2005 and August 2010. All patients had complete preoperative clinical and functional data. Baseline EF was assessed on the day before surgery by the EF domain of the IIEF-EF. All patients were stratified as follows: $1-10$ severe ED, 11-16 moderated ED; 17-21 mild-to-moderate ED; 22-25 mild ED and $\geq 26$ normal EF. ${ }^{13}$ Preoperative urinary function was evaluated with the IPSS. Patients were categorized according to validated scores as follows: 0-7 (no/mild symptoms), $8-19$ (moderate), $\geq 20$ (severe).${ }^{14} \mathrm{BMI}$ was prospectively recorded in all patients before surgery.

Indication for neurovascular bundles preservation was based on PCa characteristics at diagnosis (namely, cT1-T2a disease, biopsy Gleason score equal to or less than $3+4$, PSA $<10 \mathrm{ng} / \mathrm{mL}$ ), regardless of preoperative erectile and urinary function. All patients were treated with BNSRP carried out by a group of seven surgeons using a standardized technique. All patients were strongly recommended to attempt sexual intercourse as soon as possible after catheter removal and all of them were offered PDE5-I to encourage the recovery of EF. Patients were retrospectively divided into three groups according to the postoperative treatment: patients not using PDE5-I (group 1), patients using a full dose of PDE5-I on demand (group 2) and patients using PDE5-I daily for 3-6 months starting from the first month after surgery (group 3 ).
After the removal of the catheter, all patients were strongly encouraged to start pelvic floor muscle exercise in order to improve UC recovery after surgery. ${ }^{15}$

For the aim of the present study, patients who recovered UC before the initiation of PDE5-I treatment (namely, at 1 month after BNSRRP) were excluded $(n=52)$. Furthermore, patients with postoperative biochemical recurrence of $\mathrm{PCa}$ were excluded from our analyses. This resulted in an overall studied population of 341 men.

Postoperative UC was defined as being completely pad free over a period of $24 \mathrm{~h} .{ }^{16}$ Patients were evaluated every 3 months during the first year after surgery, and every 6 months thereafter.

\section{Statistical analyses}

Kaplan-Meier curves assessed time to UC recovery after surgery in the overall population, as well as according to postoperative use and schedule of PDE5-I. The log-rank test was used to compare the rates of UC recovery over time among the three groups. The association between PDE5-I use and UC recovery was also tested in univariable and multivariable Cox regression models. Covariates consisted of preoperative predictors of UC recovery (age at surgery, BMI, preoperative IPSS and IIEF-EF) and pathological characteristic of the disease (PSA at diagnosis and pathological stage distribution).

Statistical analyses were carried out with SPSS (SPSS, Chicago, IL, USA) version 17, with a two-sided significance level set at $P<0.05$.

\section{Results}

Clinical and pathological characteristics of patients included in the study are shown in Table 1.

Mean time of catheter removal after surgery was 8.6 days (median 8 days, range $6-15$ days).

Although all patients were recommended to use PDE5-I starting from 30 days after surgery in order to improve $\mathrm{EF}$, $171(50.2 \%)$ of them did not use any pro-erectile medication (group 1). The remaining $170(49.8 \%)$ decided to be treated. Of these, 112 (65.8\%) used PDE5-I on-demand (group 2), whereas 58 (34.2\%) used PDE5-I on a daily basis (group 3). Among patients taking PDE5-I on demand, 47 (42\%), 13 $(11.6 \%)$ and $52(46.4 \%)$ used tadalafil $20 \mathrm{mg}$, vardenafil $20 \mathrm{mg}$ and sildenafil $100 \mathrm{mg}$, respectively. In this group of patients, the mean number of doses taken over the entire period of therapy was 1.4 per week. All patients treated with daily PDE5-I used tadalafil.

At a mean follow up of 36.4 months after surgery (median 33), 288 patients $(84.5 \%)$ recovered UC after BNSRP. Overall, UC recovery rates at 1 - and 2-year follow up were $77.3 \%$ and $85.9 \%$, respectively (Fig. 1a). When patients were stratified according to the use of PDE5-I, the 1- and 
Table 1 Clinical characteristics and descriptive statistics of patients included in the study

\begin{tabular}{|c|c|c|c|c|c|c|}
\hline & $\begin{array}{l}\text { All } \\
\text { patients } \\
(n=341) \\
n(\%)\end{array}$ & $\begin{array}{l}\text { Patients not } \\
\text { using PDE5-I } \\
(n=171) \\
n(\%)\end{array}$ & $\begin{array}{l}\text { Patients using } \\
\text { PDE5-I } \\
(n=170) \\
n(\%)\end{array}$ & $P$-value & $\begin{array}{l}\text { Patients using } \\
\text { PDE5-i on demand } \\
(n=112) \\
n(\%)\end{array}$ & $\begin{array}{l}\text { Patients using } \\
\text { PDE5-I daily } \\
(n=58) \\
n(\%)\end{array}$ \\
\hline Age at surgery (years): & & & & $<0.001$ & & \\
\hline Mean (median) & $61.3(61.1)$ & $62.8(63)$ & $59.8(59.7)$ & & $60.1(59.9)$ & $59.1(59.2)$ \\
\hline Range & $45.6-85.1$ & $46.4-85.1$ & $45.6-71.8$ & & $45.6-71.8$ & $46.5-70.3$ \\
\hline$<60$ & $147(43.2)$ & $59(34.5)$ & $88(51.8)$ & & $58(51.8)$ & $30(51.7)$ \\
\hline $60-69.9$ & $165(48.3)$ & $89(52)$ & $76(44.7)$ & & $49(43.8)$ & $27(46.6)$ \\
\hline$\geq 70$ & $29(8.5)$ & $23(13.5)$ & $6(3.5)$ & & $5(4.4)$ & $1(1.7)$ \\
\hline BMI $\left(\mathrm{kg} / \mathrm{m}^{2}\right)$ : & & & & 0.17 & & \\
\hline Mean (median) & $25.6(25.4)$ & $25.7(25.5)$ & $25.4(25.1)$ & & $25.4(25.1)$ & $25.6(25.1)$ \\
\hline Range & $17.3-35.4$ & $18.3-34.4$ & $17.3-35.4$ & & $20.3-35.4$ & $17.3-33.4$ \\
\hline$<25$ & $146(42.8)$ & $65(38.2)$ & $81(47.4)$ & & $54(48)$ & $27(46.3)$ \\
\hline $25-30$ & $177(51.7)$ & $94(54.8)$ & $83(48.7)$ & & $54(48)$ & $29(50)$ \\
\hline$>30$ & $18(5.5)$ & $12(7)$ & $6(3.9)$ & & $4(4)$ & $2(3.7)$ \\
\hline Total PSA at diagnosis $(\mathrm{ng} / \mathrm{mL})$ : & & & & 0.06 & & \\
\hline Mean (median) & $7.2(5.9)$ & $7.8(6.1)$ & $6.6(5.7)$ & & $6.4(5.3)$ & $7.1(6.2)$ \\
\hline Range & $0.6-54$ & $0.6-54$ & $0.6-29$ & & $0.6-29$ & $1-28.6$ \\
\hline Pathological stage distribution: & & & & 0.09 & & \\
\hline рT2 & $283(83)$ & $138(80.7)$ & $145(85.3)$ & & $94(83.9)$ & $51(87.9)$ \\
\hline рT3a & $38(11.1)$ & $19(11.1)$ & 19 (11.2) & & $12(10.7)$ & $7(12.1)$ \\
\hline pT3b & $20(5.9)$ & $14(8.2)$ & $6(3.5)$ & & $6(5.4)$ & $0(0)$ \\
\hline Pathological Gleason score: & & & & 0.13 & & \\
\hline $2-6$ & $171(50.1)$ & $78(45.6)$ & $93(54.8)$ & & $62(55.5)$ & $31(53.6)$ \\
\hline 7 & $152(44.5)$ & $81(47.3)$ & $71(41.6)$ & & $45(40)$ & $26(44.6)$ \\
\hline $8-10$ & $18(5.4)$ & $12(7.1)$ & $6(3.6)$ & & $5(4.5)$ & $1(1.8)$ \\
\hline Preoperative IIEF-EF: & & & & 0.001 & & \\
\hline Mean (median) & $19.8(25)$ & $17.5(22)$ & $22(27)$ & & $22(27)$ & $22.2(27)$ \\
\hline Range & $1-30$ & $1-30$ & $1-30$ & & $1-30$ & $1-30$ \\
\hline 1-10 (severe ED) & $89(26)$ & $56(32.7)$ & $33(19.4)$ & & $21(18.8)$ & $12(20.7)$ \\
\hline 11-17 (moderate ED) & $22(6.7)$ & $14(8.8)$ & $8(4.7)$ & & $7(6.3)$ & $1(1.7)$ \\
\hline 18-21 (mild to moderate ED) & $16(4.7)$ & $12(7)$ & $4(2.4)$ & & $0(0)$ & $4(6.9)$ \\
\hline 22-25 (mild ED) & $53(15.2)$ & $24(13.5)$ & $29(17.1)$ & & $20(17.8)$ & $9(15.5)$ \\
\hline$\geq 26$ (no ED) & $161(47.4)$ & $65(38)$ & $96(56.4)$ & & $64(57.1)$ & $32(55.2)$ \\
\hline Preoperative IPSS: & & & & 0.06 & & \\
\hline Mean (median) & $8.9(7)$ & $9.9(8)$ & $7.9(6.5)$ & & $8.2(6)$ & $7.3(7)$ \\
\hline Range & 0-33 & $0-33$ & 0-33 & & $0-33$ & $0-22$ \\
\hline $0-7$ & $184(54.1)$ & $84(49.1)$ & $100(59.2)$ & & $64(57.4)$ & $36(62.5)$ \\
\hline $8-19$ & $120(35.2)$ & $62(36.2)$ & $58(34.1)$ & & $38(34.3)$ & $20(33.9)$ \\
\hline$\geq 20$ & $37(10.7)$ & $25(14.7)$ & $12(6.7)$ & & $10(8.3)$ & 2 (3.6) \\
\hline
\end{tabular}

Patients are tabulated according to the use of PDE5-I.

2-year UC recovery rates were $67.1 \%$ and $76 \%$ for patients not using PDE5-I versus $86.7 \%$ and $94.4 \%$ for patients using PDE5-I, respectively (Fig. 1b; log-rank: $P<0.001$ ). No significant differences were found in the 1- and 2-year UC recovery rates based on PDE5-I treatment administration schedule (Fig. 1c; log-rank: $P=0.52$ ). Table 2 shows univariable and multivariable Cox regression analyses predicting UC recovery after surgery. At univariable analyses, age at surgery and PDE5-I use represented significant predictors of UC recovery after RP (all $P<0.002$ ). These results were confirmed at multivariable analysis, where the use of PDE5-I, as well as age at surgery and BMI (all $P<0.01$ ), was independently associated with $\mathrm{UC}$ recovery $(P=0.03)$. Table 2 shows univariable and multivariable Cox regression analyses predicting UC recovery after BNSRP among patients not using any pro-erectile medication or using 
(a)

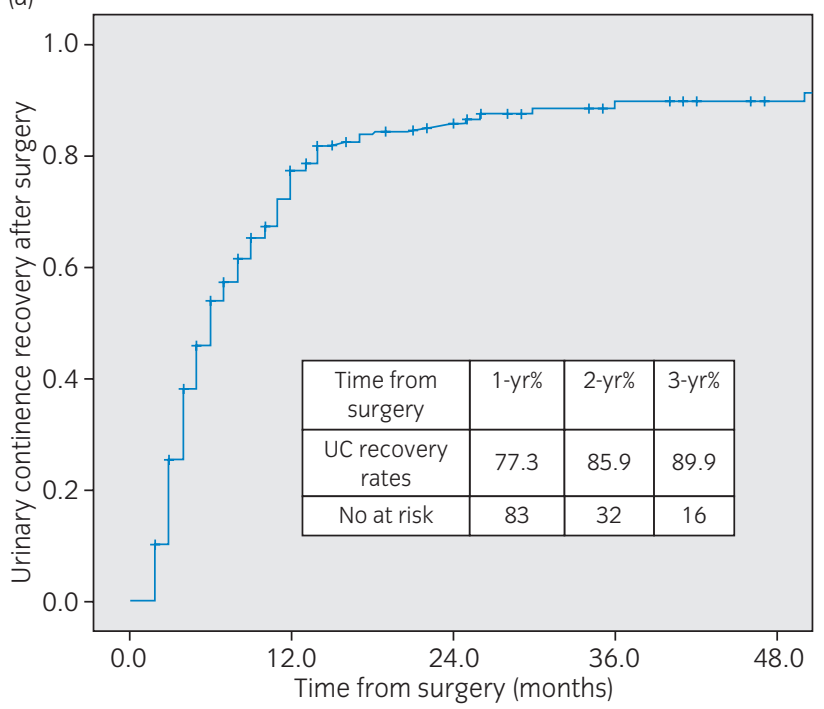

(b)

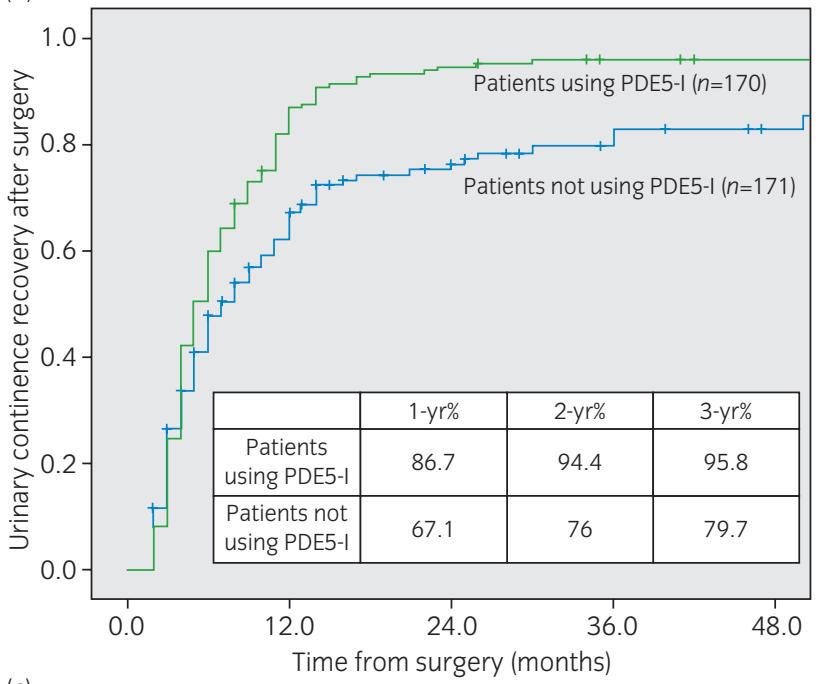

(c)

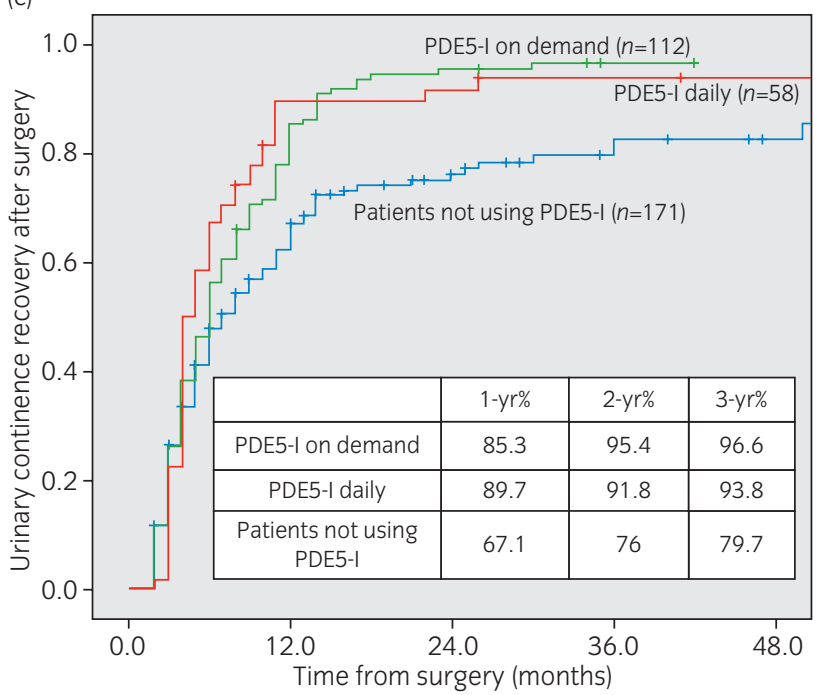

Fig. 1 (a) Kaplan-Meier curve. Overall urinary continence recovery rates (defined as usage of no pads) after BNSRP. (b) Kaplan-Meier curve. Urinary continence recovery rates according to the use of PDE5-I after BNSRP $(P<0.001)$. (c) Kaplan-Meier curve. Urinary continence recovery rates according to the PDE5-I administration schedule after BNSRP $(P<0.001)$.

PDE5-I on a daily basis. The use of PDE5-I was also a significant predictor of UC recovery in this subcohort of patients $(P=0.03)$.

\section{Discussion}

Urinary incontinence after RP remains one of the most bothersome sequelae affecting health-related quality of life after surgery, and affects between 1 and $25 \%$ of patients treated with RP. ${ }^{17-20}$ Previous studies have extensively shown that UC recovery depends on several parameters, including the type of definition used, several pre- and postoperative factors, as well as surgical technique. ${ }^{17-22}$ Although several reports have tested the impact of behavioral therapy on UC recovery, ${ }^{23,24}$ few data are available on the effect of pharmacological therapy on UC after RP. In this context, the use of PDE5-I has been suggested in a small pilot study. ${ }^{12}$ The rationale for the use of PDE5-I in improving UC recovery might reside in increased pelvic blood flow and oxygen supply, with a beneficial effect on sphincter function. However, data on PDE5-I on UC recovery are scarce and based on a very limited patient population. ${ }^{12}$

In the present study, we evaluated the impact of several parameters on UC recovery, including postoperative PDE5-I administration, in a large cohort of prospectively assessed patients treated with BNSRP at a single high-volume referral center. For the purposes of the present study, we excluded patients who recovered UC before PDE5-I treatment initiation. Therefore, all patients included were still affected by various degrees of UI when treatment with PDE5-I was started. First, we evaluated the UC recovery rate, defined as being completely pad free over a period of $24 \mathrm{~h}$. We found an overall 2-year UC recovery rate of roughly $86 \%$. As previously reported, ${ }^{17,25}$ the vast majority of patients recovered UC within the first year after surgery. Second, we tested the association between PDE5-I use and UC using KaplanMeier analysis, as well as univariable and multivariable Cox regression models. Patients using PDE5-I had significantly higher rates of UC recovery as compared with patients left untreated. However, no significant differences were found between the on demand and the daily administration schedule. Interestingly, administration of PDE5-I was also associated with UC at multivariable analyses, even after accounting for all cofounders. Remarkably, patients using 
Table 2 Univariable and multivariable Cox regression analyses predicting UC recovery (defined as use of no pads) after BNSRP and BNSRP among patients not using PDE5-I or using PDE5-I on a daily basis

\begin{tabular}{|c|c|c|}
\hline \multirow[t]{2}{*}{ Predictors } & \multirow{2}{*}{$\begin{array}{l}\begin{array}{l}\text { Univariable } \\
\text { analyses }\end{array} \\
\text { HR; P-value }\end{array}$} & \multirow{2}{*}{$\begin{array}{l}\text { Multivariable } \\
\text { analyses } \\
\text { HR; P-value }\end{array}$} \\
\hline & & \\
\hline \multicolumn{3}{|l|}{ BNSRP } \\
\hline Age at surgery (years): & $-; 0.002$ & $-; 0.01$ \\
\hline$<60$ vs $\geq 70$ & $2.3 ; 0.001$ & $2.3 ; 0.004$ \\
\hline $60-69.9$ vs $\geq 70$ & $1.8 ; 0.02$ & $1.9 ; 0.02$ \\
\hline BMI $\left(\mathrm{kg} / \mathrm{m}^{2}\right):$ & $-; 0.09$ & $-; 0.01$ \\
\hline$<25$ vs $>30$ & $0.8 ; 0.17$ & $0.6 ; 0.08$ \\
\hline $25-30$ vs $>30$ & $1.4 ; 0.17$ & $0.4 ; 0.07$ \\
\hline \multicolumn{3}{|l|}{ Pathological stage distribution } \\
\hline OC vs non-OC disease & $1.0 ; 0.56$ & $1.1 ; 0.4$ \\
\hline Total PSA at diagnosis & $0.8 ; 0.99$ & $1.0 ; 0.2$ \\
\hline $\begin{array}{l}\text { PDE5-I use according to } \\
\text { administration schedule }\end{array}$ & $-; 0.001$ & $-; 0.03$ \\
\hline $\begin{array}{l}\text { PDE5-I on-demand vs no } \\
\text { PDE5-I }\end{array}$ & $1.5 ; 0.002$ & $1.5 ; 0.04$ \\
\hline PDE5-I daily vs no PDE5-I & $1.6 ; 0.004$ & $1.5 ; 0.02$ \\
\hline Preoperative IPSS & $-; 0.06$ & $-; 0.07$ \\
\hline $0-7$ vs $\geq 20$ & $1.3 ; 0.166$ & $1.1 ; 0.5$ \\
\hline 8-19 vs $\geq 20$ & $0.9 ; 0.78$ & $0.8 ; 0.5$ \\
\hline \multicolumn{3}{|l|}{ Preoperative IIEF-EF } \\
\hline$\geq 26$ vs $0-25$ & $1.2 ; 0.1$ & $1.1 ; 0.5$ \\
\hline \multicolumn{3}{|c|}{$\begin{array}{l}\text { BNSRP among patients not using PDE5-I or using PDE5-I on } \\
\text { a daily basis }\end{array}$} \\
\hline Age at surgery (years) & $-; 0.009$ & $-; 0.04$ \\
\hline$<60$ vs $\geq 70$ & $2.5 ; 0.002$ & $2.3 ; 0.01$ \\
\hline 60-69.9 vs $\geq 70$ & $2 ; 0.02$ & $1.9 ; 0.04$ \\
\hline BMI $\left(\mathrm{kg} / \mathrm{m}^{2}\right)$ & $-; 0.3$ & $-; 0.07$ \\
\hline$<25$ vs $>30$ & $0.7 ; 0.2$ & $0.5 ; 0.09$ \\
\hline $25-30$ vs $>30$ & $0.6 ; 0.1$ & $0.4 ; 0.08$ \\
\hline \multicolumn{3}{|l|}{ Pathological stage distribution } \\
\hline OC vs non-OC disease & $1.2 ; 0.4$ & $1.3 ; 0.3$ \\
\hline Total PSA at diagnosis & $1 ; 0.6$ & $1 ; 0.8$ \\
\hline \multicolumn{3}{|l|}{ PDE5-I use } \\
\hline PDE5-I daily vs no PDE5-I & $1.5 ; 0.01$ & $1.5 ; 0.03$ \\
\hline Preoperative IPSS & $-; 0.07$ & $-; 0.1$ \\
\hline $0-7$ vs $\geq 20$ & $1.4 ; 0.3$ & $1.2 ; 0.5$ \\
\hline $8-19$ vs $\geq 20$ & $0.9 ; 0.8$ & $0.9 ; 0.5$ \\
\hline \multicolumn{3}{|l|}{ Preoperative IIEF-EF } \\
\hline$\geq 26$ vs $0-25$ & $0.9 ; 0.4$ & $1 ; 0.9$ \\
\hline
\end{tabular}

PDE5-I had roughly 1.5-fold higher probability of UC recovery as compared with patients not using PDE5-I.

These results were also confirmed when carrying out separate analyses in a subcohort of patients not using any pro-erectile medication or using PDE5-I chronically.
Several results of the present study are noteworthy. First, we confirm previous preliminary data reporting a positive effect of PDE5-I on urinary function after surgery. Gacci et al. showed that vardenafil, especially when taken nightly, was able to significantly improve urinary function as compared with placebo in men treated with BNSRP. ${ }^{12}$ However, despite the prospective study design, the trial was limited by the low number of patients enrolled $(n=39)$. We tried to circumvent this limitation by including a relative large prospectively assessed patient population $(n=341)$, treated at a high-volume center and by a large number of experienced surgeons. Interestingly, the beneficial effect of PDE5-I administration on UC recovery was confirmed even after accounting for several preoperative parameters. Explanations for our findings might be found in previous preclinical research. Indeed, PDE5 has been shown to be ubiquitously expressed in the lower urinary tract, including prostate, urethra and bladder. ${ }^{10}$ In particular, Filippi et al. reported that PDE5 expression was localized within the smooth muscle fibers of blood vessels of both the human and rat bladder. ${ }^{9}$ The role of PDE5 within these vessels was suggested to be associated with vascular tone regulation. Previous animal studies have shown that acute PDE5-I administration might lead to a reduction in vesiculardeferential artery contractile tone and increased prostate oxygenation. ${ }^{10}$ Thus, PDE5-I administration would lead to vascular smooth muscle relaxation, with a consequent vasodilatation of vessels involved in the blood supply of the prostate, urethra and bladder neck. As it has been reported that RP decreases membranous urethral blood flow, ${ }^{26}$ we can speculate that PDE5 inhibition is able to counteract such surgical induced deleterious effects by ameliorating pelvic floor blood and oxygen supply. The association between vascular status and UC after surgery has indirectly been confirmed by previous retrospective clinical studies. These reports showed an association between preoperative EF (a proxy of vascular status) and UC after NSRP. ${ }^{20,21}$ Wille et al. identified ED before RP as a prognostic factor for UC recovery after surgery in their series of 403 patients. ${ }^{21}$

Second, we also confirmed previous findings about the role of age and obesity on UC after surgery. ${ }^{18-20,22,27}$ Interestingly, both variables can also be considered as markers of patient vascular status. Higher age and BMI might indeed be associated with worse pelvic vascular status, thus leading to a reduction in sphinteric and pelvic blood flow and, consequently, to lower UC recovery rates after surgery. Taken together, all these observations seem to suggest a rationale for increasing pelvic vascular supply after surgery in order to improve both erectile and urinary function. Furthermore, a recent review of prospective studies on the administration of PDE5-I for the treatment of LUTS in patients affected by benign prostatic hyperplasia showed that the degree of improvement in IPSS depends on baseline IPSS, age and BMI. ${ }^{28}$ In this context, obesity and older age are associated 
with a reduction of testosterone serum levels, ${ }^{29,30}$ which could in turn decrease the expression of PDE5, ${ }^{31,32}$ reducing the usefulness of PDE5-I administration in this group of patients.

Despite several strengths, the present study was limited by its retrospective design. Also, the use of PDE5-I might have been influenced by patient and surgeon discussion about possible treatment options and expectations, thus potentially introducing a patient selection bias in the analyses. Patients who decided to use PDE5-I after surgery were younger and had lower rates of ED preoperatively. Even if such differences in the mentioned variables have been accounted for in multivariable models, we cannot exclude that other unmeasured variables might have influenced the results of our analyses. In this context, it is possible that patients using PDE5-I might reflect a subgroup of patients that are more motivated to reach functional recovery after BNSRP. Unfortunately, the degree of urinary incontinence after surgery (before treatment initiation) was not collected in our database. It cannot be excluded that those patients that used PDE5-I might have had a lower degree of UC in the immediate postoperative period. Furthermore, at multivariable analysis preoperative IPSS was borderline significant for the prediction of UC recovery after surgery. The use of specific questionnaires for prostate cancer (i.e. UCLA-PCI) for the quantification of urinary function and bother could be significantly associated with the recovery of UC after BNSRP. $^{33}$ However, these data are not available for our patients.

Finally, all patients were treated with BNSRP at a highvolume center by experienced surgeons. Therefore, the present results could differ from those derived from other clinical settings. Despite these limitations, the present study represents the only large retrospective report testing the association between PDE5-I administration and UC recovery in a population of patients treated with BNSRP.

In conclusion, the use of PDE5-I significantly improved UC recovery after BNSRP regardless of the treatment administration schedule. As PDE5 is ubiquitously expressed in the lower urinary tract, the beneficial effect of PDE5-I on UC recovery might reside on increased pelvic blood flow and oxygen supply, with a beneficial effect to sphincter function. However, well conducted, prospective randomized trials are required to confirm these preliminary, retrospective findings.

\section{Conflict of interest}

None declared.

\section{References}

1 Heidenreich A, Bellmunt J, Bolla M et al. EAU guidelines on prostate cancer. Part 1: screening, diagnosis, and treatment of clinically localised disease. Eur. Urol. 2011; 59: 61-71.

2 Sanda MG, Dunn RL, Michalski J et al. Quality of life and satisfaction with outcome among prostate-cancer survivors. N. Engl. J. Med. 2008; 358: 1250-61.

3 Shao YH, Demissie K, Shih W et al. Contemporary risk profile of prostate cancer in the United States. J. Natl. Cancer Inst. 2009; 101: 1280-3.

4 Dubbelman YD, Dohle GR, Schroder FH. Sexual function before and after radical retropubic prostatectomy: a systematic review of prognostic indicators for a successful outcome. Eur. Urol. 2006; 50: 711-18; discussion 718-20.

5 Bannowsky A, Schulze H, van der Horst C, Hautmann S, Junemann KP. Recovery of erectile function after nerve-sparing radical prostatectomy: improvement with nightly low-dose sildenafil. BJU Int. 2008; 101: 1279-83.

6 Montorsi F, Brock G, Lee J et al. Effect of nightly versus on-demand vardenafil on recovery of erectile function in men following bilateral nerve-sparing radical prostatectomy. Eur. Urol. 2008; 54: 924-31.

7 Waldkirch ES, Uckert S, Langnase $\mathrm{K}$ et al. Immunohistochemical distribution of cyclic GMP-dependent protein kinase-1 in human prostate tissue. Eur. Urol. 2007; 52: 495-501.

8 Fibbi B, Morelli A, Vignozzi L et al. Characterization of phosphodiesterase type 5 expression and functional activity in the human male lower urinary tract. J. Sex. Med. 2010; 7 (1 Pt 1): 59-69.

9 Filippi S, Morelli A, Sandner P et al. Characterization and functional role of androgen-dependent PDE5 activity in the bladder. Endocrinology 2007; 148: 1019-29.

10 Morelli A, Sarchielli E, Comeglio P et al. Phosphodiesterase type 5 expression in human and rat lower urinary tract tissues and the effect of tadalafil on prostate gland oxygenation in spontaneously hypertensive rats. J. Sex. Med. 2011; 8: 2746-60.

11 Martinez-Salamanca JI, Carballido J, Eardley I et al. Phosphodiesterase type 5 inhibitors in the management of non-neurogenic male lower urinary tract symptoms: critical analysis of current evidence. Eur. Urol. 2011; 60: 527-35.

12 Gacci M, Ierardi A, Rose AD et al. Vardenafil can improve continence recovery after bilateral nerve sparing prostatectomy: results of a randomized, double blind, placebo-controlled pilot study. J. Sex. Med. 2010; 7 (1 Pt 1): $234-43$.

13 Cappelleri JC, Rosen RC, Smith MD, Mishra A, Osterloh IH. Diagnostic evaluation of the erectile function domain of the International Index of Erectile Function. Urology 1999; 54: 346-51.

14 Homma Y, Kawabe K, Tsukamoto T et al. Estimate criteria for diagnosis and severity in benign prostatic hyperplasia. Int. J. Urol. 1996; 3: 261-6.

15 Centemero A, Rigatti L, Giraudo D et al. Preoperative pelvic floor muscle exercise for early continence after radical prostatectomy: a randomised controlled study. Eur. Urol. 2010; 57: 1039-43.

16 Box GN, Ahlering TE. Robotic radical prostatectomy: long-term outcomes. Curr. Opin. Urol. 2008; 18: 173-9. 
17 Touijer K, Eastham JA, Secin FP et al. Comprehensive prospective comparative analysis of outcomes between open and laparoscopic radical prostatectomy conducted in 2003 to 2005. J. Urol. 2008; 179: 1811-17.

18 Kundu SD, Roehl KA, Eggener SE, Antenor JA, Han M, Catalona WJ. Potency, continence and complications in 3,477 consecutive radical retropubic prostatectomies. J. Urol. 2004; 172 (6 Pt 1): 2227-31.

19 Stanford JL, Feng Z, Hamilton AS et al. Urinary and sexual function after radical prostatectomy for clinically localized prostate cancer: the Prostate Cancer Outcomes Study. JAMA 2000; 283: 354-60.

20 Gandaglia G, Suardi N, Gallina A et al. Preoperative erectile function represents a significant predictor of postoperative urinary continence recovery in patients treated with bilateral nerve sparing radical prostatectomy. J. Urol. 2012; 187: 569-74.

21 Wille S, Heidenreich A, Hofmann R, Engelmann U. Preoperative erectile function is one predictor for post prostatectomy incontinence. Neurourol. Urodyn. 2007; 26: 140-3.

22 Gacci M, Lapini A, Serni S et al. Predictors of quality of life after radical treatment for prostate cancer. Urol. Int. 2008; 80: 231-6.

23 Goode PS, Burgio KL, Johnson TM II et al. Behavioral therapy with or without biofeedback and pelvic floor electrical stimulation for persistent postprostatectomy incontinence: a randomized controlled trial. JAMA 2011; 305: 151-9.

24 Ribeiro LH, Prota C, Gomes CM et al. Long-term effect of early postoperative pelvic floor biofeedback on continence in men undergoing radical prostatectomy: a prospective, randomized, controlled trial. J. Urol. 2010; 184: 1034-9.
25 Abdollah F, Sun M, Suardi N et al. Prediction of functional outcomes after nerve-sparing radical prostatectomy: results of conditional survival analyses. Eur. Urol. 2012; 62: $42-52$.

26 John H, Suter S, Hauri D. Effect of radical prostatectomy on urethral blood flow. Urology 2002; 59: 566-9.

27 Wolin KY, Luly J, Sutcliffe S, Andriole GL, Kibel AS. Risk of urinary incontinence following prostatectomy: the role of physical activity and obesity. J. Urol. 2010; 183: 629-33.

28 Gacci M, Corona G, Salvi M et al. A systematic review and meta-analysis on the use of phosphodiesterase 5 inhibitors alone or in combination with alpha-blockers for lower urinary tract symptoms due to benign prostatic hyperplasia. Eur. Urol. 2012; 61: 994-1003.

29 Corona G, Mannucci E, Forti G, Maggi M. Hypogonadism, ED, metabolic syndrome and obesity: a pathological link supporting cardiovascular diseases. Int. J. Androl. 2009; 32: 587-98.

30 Corona G, Rastrelli G, Morelli A, Vignozzi L, Mannucci E, Maggi M. Hypogonadism and metabolic syndrome. J. Endocrinol. Invest. 2011; 34: 557-67.

31 Morelli A, Filippi S, Sandner P et al. Vardenafil modulates bladder contractility through cGMP-mediated inhibition of RhoA/Rho kinase signaling pathway in spontaneously hypertensive rats. J. Sex. Med. 2009; 6: 1594-608.

32 Blute M, Hakimian P, Kashanian J, Shteynshluyger A, Lee M, Shabsigh R. Erectile dysfunction and testosterone deficiency. Front. Horm. Res. 2009; 37: 108-22.

33 Litwin MS, Hays RD, Fink A, Ganz PA, Leake B, Brook RH. The UCLA Prostate Cancer Index: development, reliability, and validity of a health-related quality of life measure. Med. Care 1998; 36: 1002-12.

\section{Editorial Comment}

\section{Editorial Comment to Postoperative phosphodiesterase type 5 inhibitor administration increases the rate of urinary continence recovery after bilateral nerve-sparing radical prostatectomy}

The authors investigated the effects of phosphodiesterase type 5 inhibitors (PDE5-I) on urinary continence recovery after bilateral nerve-sparing radical prostatectomy (BNSRP) in a retrospective study on 393 men. ${ }^{1}$ They concluded that men taking PDE5-I had higher continence recovery rates as compared with those untreated after BNSRP, suggesting that an improvement in sphincteric and pelvic floor blood supply could be responsible for this PDE5-I dependent effect.

The present article's strength is the large population of the study, recruited in a single tertiary referral center for prostate cancer, investigated preoperatively with a detailed data setting (including baseline International Prostate Symptoms Score [IPSS] and Body Mass Index [BMI]), treated exclusively with BNSRP, managed with short catheterization time (median 8 days) and with subsequent standardized muscle exercise to improve continence recovery without hormone manipulation for postoperative biochemical failure, and followed up for 3 years. The few limits of this study are the absence of a grading of severity of postprostatectomy urinary incontinence (such as "No pad", "1 